\title{
Pulmonary Thromboembolism Following Splenectomy in Hereditary Spherocytosis
}

\author{
Amitesh Aggarwal $^{a}$, Vishal Sharma ${ }^{\mathrm{a}, \mathrm{b}}$, Shridhar Dwivedi ${ }^{\mathrm{a}}$
}

\begin{abstract}
Hereditary spherocytosis is an inherited disorder characterized by presence of spherocytes. It usually manifests clinically as triad of anaemia, splenomegaly and jaundice. The recommended treatment in a symptomatic patient is splenectomy. Occurrence of pulmonary thromboembolism in hereditary spherocytosis following splenectomy is unusual. We report the case of a 30 year old male who underwent splenectomy for hereditary spherocytosis and subsequently developed pulmonary thromboembolism and right ventricular mural thrombosis six years later. His showed no other procoagulant disorders. The development of pulmonary thromboembolism and right ventricular mural thrombosis in a patient of hereditary spherocytosis after splenectomy is an interesting association.
\end{abstract}

Keywords: Hereditary spherocytosis; Splenectomy; Pulmonary thromboembolism; Spherocytosis

\section{Introduction}

Hereditary spherocytosis (HS) is a type of hemolytic anaemia resulting from a defect in membrane-cytoskeleton of red blood corpuscles (RBCs). It results from molecular defects in one of the proteins in cytoskeleton of RBC membrane. The disease, usually autosomal dominant, can also be inherited in autosomal recessive pattern. It manifests clinically as a triad of anemia, splenomegaly and jaundice. However, development of pulmonary thromboembolism in hereditary spherocytosis is unusual.

\footnotetext{
Manuscript accepted for publication June 4, 2010

${ }^{\text {a}}$ Department of Medicine, University College of Medical Sciences and GTB Hospital, Delhi, India

${ }^{\text {b}}$ Corresponding author: 19 Gobind Nagar, Subhash Road Chheharta, Amritsar, Punjab, India. Email: docvishalsharma@gmail.com
}

doi:10.4021/jmc2010.06.102e

\section{Case Report}

An unmarried 36 year old male presented to us with chief complaints of left lower limb swelling and tenderness along with breathlessness on exertion for past 7 days. He was symptomatic for anemia 6 years back and was diagnosed as a case of moderate hereditary spherocytosis. At that time his upper GI endoscopy, barium meal study, direct and indirect Coomb's test, methaemoglobin reduction test for G6PD, hemoglobin electrophoresis, Heinz body test, BT/CT/PT/ PTTK was done with negative results. Osmotic fragility was increased. He underwent splenectomy with subsequent recovery. His mother and sister were screened for hereditary spherocytosis with negative result. No genetic studies were done.

The physical examination at the time of admission revealed tachycardia, tachypnoea, normotension with raised JVP. Systemic examination revealed right ventricular S3, clear lungs and mild tender hepatomegaly. Left lower limb showed superficial thrombophlebitis in the distribution of great saphenous vein. Homan's sign was negative.

Lab investigations including complete blood count were unremarkable. Peripheral blood film was suggestive of spherocytosis with increased nucleated RBC's and Howell Jolly bodies. ABG and thyroid profile was within normal limits. ECG showed sinus tachycardia with right ventricular strain pattern. Lower limb Doppler studies failed to show any evidence of thrombus in proximal veins. Chest x-ray and fundus examination were unremarkable. Echocardiographic studies revealed dilated RV and RA, PA pressure of 75, reversal of $\mathrm{E} / \mathrm{A}$ ratio, dilated IVC with poor inspiratory collapse, LVEF of $60 \%$ and decreased RV systolic function. HRCT and CECT chest showed multiple pulmonary emboli in the left main pulmonary artery and descending branch of right pulmonary artery, wedge shaped infarct in left lower lobe of lung and RV mural thrombus. Patient was started on low molecular weight hepain shifting to oral anticoagulation later on with marked symptomatic improvement in clinical symptoms. He was investigated further for presence of various coagulation disorders. Results of Protein C, Protein S, Antithrombin III, Factor V leiden, Factor VIII and Lupus 
Anticoagulant were found to be normal.

\section{Discussion}

This case is interesting as hereditary spherocytosis has not been associated with increased thrombogenicity as a sole etiology. Thrombotic events have anecdotally been reported in patients with hereditary spherocytosis, but the frequency of inherited thrombotic risk factors is high enough (particularly Factor V Leiden) in certain populations to account for concurrent occurrence $[1,2]$. Certain reports implicated hereditary spherocytosis as a cause of pulmonary embolism in association with other conditions like peripartum state, hemoglobin Newcastle and hemoglobin Constant Spring [3].

There is a suggestion that splenectomy may be associated with subsequent development of pulmonary hypertension as a result of in situ thrombosis [4]. There is some evidence from animal models that there may be a risk of thrombosis related to the abnormal red cells in mice, with both HS and hereditary elliptocytosis, but this has not, as yet, been demonstrated in humans. Moreover, the thrombosis risk is abolished in these mice by infusion of a small number of normal stem cells [5]. Some studies have shown that splenectomy done for treating hemolytic anemia predispose the patient to subsequent pulmonary thromboembolism. The Steward and co-workers have shown that in patients with hereditary stomatocytosis, splenectomy may also be a risk factor for thromboembolic complications and pulmonary hypertension [6]. Although the occurrence of pulmonary hypertension was believed to be a consequence of splenectomy, a recent report seems to challenge this notion, indicating that irrespective of whether they are splenectomised or not, the patients with haemolytic anaemia are predisposed to pulmonary hypertension probably secondary to pulmonary thromboembolism [7].

Pulmonary embolism is increasingly recognized as an infrequent complication of splenectomy in hereditary hemolytic anaemias. This diagnosis must be distinguished from pulmonary thrombosis in situ which occurs with pulmonary hypertension.

Although few reports have speculated on association of hereditary spherocytosis with pulmonary embolism, other compounding conditions were also present $[1-3,8]$. This report is important because it shows a case of hereditary spherocytosis presented with acute pulmonary embolism without evidence of pulmonary hypertension after splenectomy.

\section{Conflict of Interest}

None

\section{References}

1. Hayag-Barin JE, Smith RE, Tucker FC, Jr. Hereditary spherocytosis, thrombocytosis, and chronic pulmonary emboli: a case report and review of the literature. Am J Hematol 1998;57(1):82-84.

2. Nikol S, Huehns TY, Kiefmann R, Hofling B. Excessive arterial thrombus in spherocytosis. A case report. Angiology 1997;48(8):743-748.

3. Au WY, Ma ES. Peripartum pulmonary embolism in a patient with concomitant hemoglobin Newcastle, hemoglobin Constant Spring, and hereditary spherocytosis. Am J Hematol 2005;80(2):166.

4. Hoeper MM, Niedermeyer J, Hoffmeyer F, Flemming P, Fabel H. Pulmonary hypertension after splenectomy? Ann Intern Med 1999;130(6):506-509.

5. Wandersee NJ, Lee JC, Deveau SA, Barker JE. Reduced incidence of thrombosis in mice with hereditary spherocytosis following neonatal treatment with normal hematopoietic cells. Blood 2001;97(12):3972-3975.

6. Stewart GW, Amess JA, Eber SW, Kingswood C, Lane PA, Smith BD, Mentzer WC. Thrombo-embolic disease after splenectomy for hereditary stomatocytosis. Br J Haematol 1996;93(2):303-310.

7. Ghosh K, Meera V, Jijina F. Pulmonary hypertension in patients with hematological disorders following splenectomy. Indian J Hematol Blood Transfus 2009;25(2):4548.

8. Karnak D, Beder S, Kayacan O, Berk O. Postoperative pulmonary embolism in a young female accompanying with Factor V Leiden mutation and hereditary sypherocytosis. J Thromb Thrombolysis 2004;17(3):213-217. 